\title{
On message
}

\section{Keeping politicians and the public informed about advances in climate science would benefit from the active participation of social scientists in the process.}

The need for more effective science communication in the context of climate change has been widely debated over recent years, with scientists and communication experts increasingly engaged in the discussion. Initiatives such as the Climate Communication project ${ }^{1}$ that operates under the Aspen Global Change Institute - an organization dedicated to advancing the scientific understanding of Earth systems and global environmental change - are growing in number. The project relies on a dedicated pool of experts to disseminate climate research, support scientists and assist journalists. At its big annual meetings, the American Geophysical Union now regularly includes workshops on climate science communication. In a similar vein, the Intergovernmental Panel on Climate Change (IPCC) approved an official communication strategy at its 35th session in Geneva in 2012, following the recommendation by the InterAcademy Council - an organization of science academies that provides knowledge and advice to national governments and international bodies such as the European Commission and the United Nations. But even so, the communication of climate science remains a challenging task.

Social scientists versed in climate change research have extensively analysed the many dimensions of climate science communication. In its first issue in 2011, Nature Climate Change published a Perspective by Nicholas Pidgeon and Baruch Fischoff $^{2}$ on the contribution of the social sciences to communicating uncertain climate risks. Since then numerous studies have appeared in the literature, suggesting various approaches to improve communication of climate science - but whether progress on the ground has been made is a different matter. Pidgeon and Fischoff reminded that the public gets to know science mainly through news reports about scientific breakthroughs. And each time people are able to connect scientific advances to improved life conditions, trust in science builds up. However, no matter how solid the science is, media reporting of climate change - and climate science more broadly - is patchy, sometimes inconsistent or even misleading. Media attention on these matters also seems to be in decline, at least in the United States, as shown by recent data from the Center for Science and Technology Policy Research at the University of Colorado in Boulder, USA ${ }^{3}$. Polls and public opinion studies show divergence of public views about climate change. Experts also argue about how public trust in climate science tends to drop after events such as 'climategate' that undermine scientists' credibility, as shown in a recent paper by Anthony Leiserowitz and colleagues ${ }^{4}$ published in the American Behavioural Scientist.

Social scientists have long pondered why it is that climate scientists find it so difficult to reach out and engage the public. One explanation widely recognized in the literature is that many of us are still unable to connect the latest scientific advances about the climate system and its changes to our everyday existence. This perceived lack of immediate relevance - 'What does it mean for me?' - is a key barrier. It is therefore fundamental to relate climate science and climate change phenomena to people's lives. But there is more to it than that. Climate scientists themselves are seen as distant, and the process by which IPCC assessment reports are produced remains a mystery to many. In fact, people are left wondering what happens behind closed doors at IPCC meetings. Sociologists of science - those interested in the analysis of the science-making process - talk with, and observe scientists at research facilities and scientific meetings to understand the ways in which knowledge is generated and assessed. In the context of climate science, such understanding could help to bridge the gap with the public and can certainly contribute to improving the communication of the science.

Recently, a group of sociologists requested permission to attend meetings of the IPCC to study its workings at close quarters ${ }^{5}$, but whether their request will be accepted is still up in the air at the time of writing. Allowing an army of expert observers could be intrusive unless carefully managed, and there are also issues of confidentiality to consider (all matters the proponents of the project are well aware of). However, the benefits of giving sociologists access to the meeting could be great. For example, permitting ethnographers to observe scientists directly at IPCC meetings and to interview them 'on the job' would be unprecedented, as previous attempts to understand the IPCC process have been based on reconstructions and after-the-fact interviews. Studying scientists' interactions from inside would surely help to increase their credibility with the public, as well as improve the perceived transparency of IPCC procedures. Just as importantly, a sociological study of IPCC experts' exchanges could help climate scientists appreciate and understand prevailing attitudes towards specific research questions, research findings and their interpretation.

Climate science needs to reach out to society in an inclusive way. Although not sufficient to induce the behavioural changes needed at societal level to avoid dangerous climate change, public acceptance of, and trust in, climate science is a necessary condition. Of course, policy needs to change as well, and it should do so in accordance with scientific knowledge. For this reason, social scientists often call for a scientific research agenda that is specifically tailored to help decision-makers. But ultimately, scientific knowledge needs to be spread across the political system for sound policy decisions to be made. And again, this all comes down to communicating the science effectively.

Political experts would argue that the cost of climate action to politicians is too high and that they will only take steps in line with science if technological and economic solutions are able to minimize such cost. However, others respond that in time of crises in the past, difficult and indeed costly political decisions were made. Perhaps what is needed is a blend of more policy-relevant science and different ways to disseminate and communicate it. Perhaps stories of human devastation, such as the dramatic impacts of recent typhoon Haiyan in South East Asia, could serve to bring climate change and climate science back to people's attention by making it tangible. Whatever the solution, societies need to make sense of climate science now. All experts, including climate and social scientists, have an important role to play in bridging the science-public gap; in short, it is time for them to join forces.

\footnotetext{
References

1. http://www.climatecommunication.org

2. Pidgeon, N. \& Fischoff, B. Nature Clim. Change 1, 35-41 (2011).

3. http://go.nature.com/NR7P2p

4. Leiserowitz, A. A., Maibach, E. W., Roser-Renouf, C., Smith, N. \& Dawson, E. Am. Behav. Sci. 5, 818-837 (2013).

5. Tollefson, J. Nature 502, 281 (2013).
} 